\title{
Advancing Dental Care: Funding vital to realise ambitions
}

The British Dental Association has said new funding is essential to realise the ambitions set out in Health Education England's Advancing Dental Care review.

The report concludes a three-year programme examining training pathways in dentistry and makes a number of recommendations for future change. The $\mathrm{BDA}$ has been involved and provided feedback on ADC proposals since its inception. The BDA has supported proposals for more flexibility in training, and shares concerns raised in the report about underserved areas. It is also supportive of working with the GDC to continue developing a more workable route for mediated entry to the specialist lists.

However, the BDA maintains concerns that plans may risk destabilising some of the existing training structures that serve

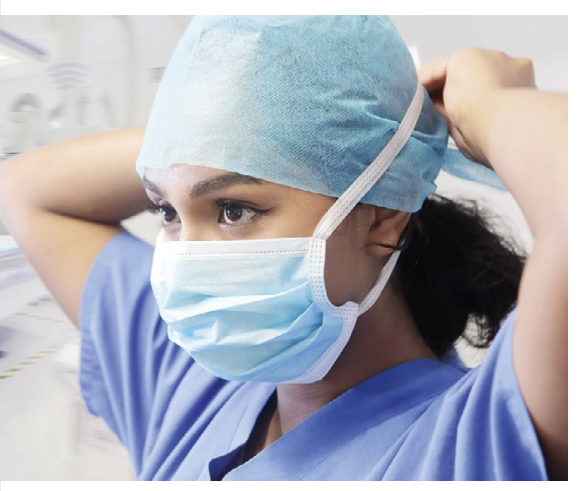

current populations. While dentist leaders were offered assurances that posts will not be taken away and reallocated, and will only be created with extra funding, the report itself does not offer guarantees. While it mentions 'new posts' the review focuses more generally on 'equitable distribution'. The BDA has also warned that creating new Centres for Dental Development will require significant investment, and that jobs must be available for those undertaking training for new qualifications.

The union remains unconvinced about some of the suggestions of how future dental teams will work, especially the suggestion that teams working with high-needs patients do not require a dentist, and reminds HEE that contract reform in England will need to lead to a more workable arrangement if the government is serious about countering the exodus of professionals from the NHS. It has also expressed disappointment that financial modelling from consultancy London Economics - on which many of the assumptions in the report are based - have not been published alongside the main report.

The report identifies 20 workstreams, covering 5 core proposals. The BDA has stressed partnership working will be fundamental going forward, given many fall outside of HEE's statutory role, a point the report itself acknowledges. The BDA has stated it expects to feed into all workstreams going forward. All relevant BDA committees will now consider the review in detail and will provide further commentary in due course.

Dr Sara Hurley, Chief Dental Officer England, said: 'This exciting new plan for the future will strengthen the capabilities and capacity of our dental teams, improve our support to patients in preventing dental disease and increase access to high quality care.'

Shareena Ilyas Chair of the British Dental Association's Education, Ethics \& Dental Team Working Group said: 'While many of the ideas and ambitions set out are laudable, there is a tangible risk plans could destabilise services across England.

'These trainees provide care to thousands of patients. 'Redistributing' existing places will only mean moving young dentists from areas already struggling to meet demand.

'All practices face huge and competing demands, and any idea we can secure new training places without new funding is pie in the sky.

'The numbers this report is based on have not yet been shared. As we move forward we need HEE to make openness the rule, and to ensure dentists have a seat at the table.'

\section{Javid pressed on support as PM pledges to 'make NHS dentistry a better place for profession'}

With Health Secretary Sajid Javid now confirmed to be staying in post following the reshuffle, the British Dental Association have issued an open letter seeking assurances on how the $£ 36$ billion recently committed to the NHS will be used to support the recovery of dental services across primary and secondary care.

The boost, funded by the new Health and Social Care Levy, was described by the Prime Minister as the 'biggest catch-up programme in the NHS's history'.

As the Prime Minister told the House of Commons he recognised the need to 'fix' NHS dentistry, stating that 'we want the NHS to be a better place for the dental profession.' In the letter, the BDA stress their commitment to work with Ministers to achieve the PM's objective.

Dental leaders are seeking clarity on the proportion of new money will be allocated to help tackle the unprecedented backlog of dental care, and enable dentists to continue to provide NHS care in the years ahead. England remains the only UK nation not to commit any capital funding for ventilation improvements to enable a safe increase in patient numbers.

Oral health inequalities are now set to widen owing to the suspension of public health programmes, and ongoing access problems. Over 30 million appointments have been lost in high street services since the first lockdown in England alone.
Recently published NHS Dental Statistics indicate the proportion of children seen by an NHS dentist in the last 12 months fell from 59\% in March 2020 to just 23\% in March 2021.

Copies of the message have been sent to the dentistry Minister Jo Churchill MP, as well Sir James Mackey, who has recently been appointed to advise on clearing the enormous backlog of elective surgery that has built up over the past 18 months - including dental procedures under general anaesthetic, where patients already faced year-long waiting times prior to COVID-19.

The letter is available here: https://bda. org/advice/Coronavirus/Documents/letterfrom-bda-to-sajid-javid-sep-21.pdf 